\title{
INTRODUCTION: \\ NEW INTERDISCIPLINARY PERSPECTIVES IN CHINESE PHILOSOPHY
}

The set of articles in this anthology establish the contemporary relevance of Chinese philosophy and emphasize the significance of its insights in an epistemological context that values interdisciplinary knowledge. ${ }^{1}$ The articles extend modern scholarship in pushing and challenging traditional disciplinary boundaries. Some of the contributors raise questions that can only be adequately addressed in interdisciplinary research, as for instance, across psychology, politics, ethics, and physiological health. Some others cast doubt on the fields traditionally set out in Western philosophy, for example, between metaphysics, ethics, epistemology, and logic and argumentation. A significant theme that arises collectively from the discussions in these articles is that there were no disciplinary divisions in early Chinese philosophy, of the sorts in Western philosophy and modern Western thought. Hence, a more careful study of early Chinese philosophy could contribute to a more meaningful understanding of the idea of interdisciplinarity.

In "On Human Consciousness in Classical Chinese Philosophy: Developing Onto-Hermeneutics of the Human Person," Chung-ying Cheng develops an original account of human consciousness on the basis of Chinese thought during the Spring and Autumn (772-476 BCE) and Warring States (475-221 BCE) periods. His account of consciousness is explained in terms of three integrated layers. The first is a conceptual awareness of the interconnectedness of entities and beings within a constantly changing cosmos, the second an understanding of oneself as a unique human individual, and the third a consciousness of self as part of political society. Cheng brings together conceptual commitment, ethics and axiology, and political participation in his conception of human consciousness. He considers a difficult issue, the tension between expressions of individuality or creativity and institutional and governmental control. He draws on the Confucian theme of the morally rectified ruler who has a heightened consciousness of the well-being of the people and the importance of their

KARYN L. LAI, Senior Lecturer, School of Philosophy, University of New South Wales. Specialties: early Confucianism and Daoism, Confucian ethics, environmental ethics. E-mail: k.lai@unsw.edu.au

(C) 2007 Journal of Chinese Philosophy 
trust. Cheng's argument utilizes a number of themes in Chinese philosophy to make the case for a more transparent and accountable government in China. This is important and timely as there is currently among the Chinese a wave of renewed interest in the indigenous philosophies of China to satisfy their ethical, spiritual, and axiological aspirations. More fundamentally, Cheng's conception of consciousness that is integrated at conceptual, ethical, and political levels may serve as the basis for a profound conception of selfhood. This view of self is important not only within Chinese philosophical studies and comparative philosophy but also in other fields of study.

In "Constructing 'Chinese Philosophy' in Sino-European Cultural Exchange," Tang Yijie examines the development of Chinese philosophy as an independent field of inquiry. He argues that what we call "Chinese philosophy" today is constituted in part by Western philosophy, through the scholarship of intellectuals such as Fung Yu-lan (Feng Youlan) and Hu Shih (Hu Shi) in the early twentieth century. Having been exposed to different streams in Western philosophy, these intellectuals proceeded to explain ideas in Chinese thought in terms of the conceptual frameworks and categories available in Western philosophy. While there are concerns about the potential misshaping of ideas in Chinese thought - and Tang is aware of them - he contends that these developments are on the whole positive. This is because, up until the early modern period, the study of Chinese thought was not clearly distinguished from studies of the classics (jingxue), studies of the doctrines of masters (zixue), and intellectual history more broadly. Although, in the early period, aspects of Chinese philosophy were interpreted in terms of categories in Western philosophy, the latter also gave form and definition to Chinese philosophy and allowed for comparative studies. Tang urges contemporary scholars now to move on from the modern beginnings of Chinese philosophy to consider its distinctive aspects. He considers a number of methodological issues and constructive strategies in comparative philosophy. These include careful articulation of ideas and translation of terms as well as dialogic interaction between Western and Chinese thought. Tang's analysis accentuates the importance of intellectual history to Chinese philosophy and the dynamic nature of this field of study.

While Tang is cautiously accepting of the influences of Western philosophy on Chinese philosophy, Nathan Sivin suggests that study of early Chinese thought must be more inclusive, and that Chinese philosophers should not artificially restrict their study of Chinese philosophy according to modern disciplinary categories. Sivin, an authority on the philosophy of Chinese science and medicine, points out in "Philosophy and Medicine" that discussions in the Huangdi Neijing texts (of the Warring States period-c. 475-221 вCE), which 
deal with medicine and health, are closely intertwined with other discussions of the same period. Sivin's article highlights the deficiencies of modern scholarship in Chinese philosophy because while it is highly developed in some respects, few Chinese philosophers have also attended to the Huangdi Neijing. This is of concern given the integration of ideas on ethics, politics, health, religion, the cosmos, and the natural world in early Chinese philosophy. Sivin encourages the integrated, horizontal study of texts that looks for and understands important connections between ideas in different texts. This also involves reading the texts with an expectation that the ideas therein express facets of real, concrete lives: "ideals, ambitions, frustrations and prejudices." Sivin makes a compelling case for Chinese philosophers to look beyond those texts that are centrally philosophical-the Analects, Daodejing, Zhuangzi, and Mozi-and, as well, to approach classical texts informed by knowledge from other disciplines including anthropology, sociology, and religious studies.

William Herfel, Dianah Rodrigues, and Yin Gao discuss the Chinese conception of disease and hold it up as a viable paradigm of how illness and health can be understood. In "Chinese Medicine and the Dynamic Conceptions of Health and Disease," the authors seek to dispel mainstream perceptions (in the Western world) that conceptions of health and disease in Chinese medicine are "unscientific," especially as contrasted with Western biomedicine. Their discussion is based on an understanding of the human body as a system that embodies dynamical relationships between the different organs. The breakdown of relationships, that is, lack of harmony between the different organs, constitutes disease. According to this view, health is understood in terms of effective harmonies between all aspects of the human body; it emphasizes resonances between the different organs. This in turn means that continuing maintenance of these relationships is the key to health. The Chinese view of maintenance of health offers a different paradigm of medicine from that in Western biomedicine that focuses overwhelmingly on the state of repair of individual, isolated organs, and on rectifying illnesses with cures. Because it focuses on the harmonizing dynamics of the entire human body, the approach of Chinese medicine may be described as holistic. But this article points out that Chinese medicine is also holistic in another way. It understands the human body as an open system whose harmony may be reinforced or disrupted by changes in its surrounding environment. In other words, this view of human health attempts, as far as possible, comprehensively to account for changes in the environment that affect an individual. Here, another important aspect of Chinese medicine emerges: it refrains from standardizing symptoms, diagnoses, or treatments. Clearly, this approach is very different from the classification of disease in Western biomedi- 
cine. It seems already apparent from this article that a dialogue between the two paradigms under a conceptual framework that is not already predisposed to one or the other, will expand and enrich our understanding of human health and medicine.

In "Understanding Change: The Interdependent Self in Its Environment," Karyn Lai suggests that there are resources in Chinese philosophy that may be helpful for psychological well-being. From ancient times, the Chinese consciousness of change, its imminence, and propensity to affect an individual, has prompted deliberation about how change can be dealt with both individually and collectively. The awareness of change is incipient in a seminal ninth-century BCE text, the Yijing (Book of Changes), and is reflected more broadly in the discussions in early philosophical texts such as the Daoist Zhuangzi and Confucius' Analects. She analyzes passages from these texts to demonstrate that these early Chinese thinkers attended to issues associated with changing situations and circumstances. These issues include, especially, the dynamics of relationships and an individual's place within a larger contextual environment. She suggests that the discussions in these early texts foster and encourage deeper and broader understanding of the vicissitudes of life. Her thesis calls for interdisciplinary research in philosophy and psychology where collaborative investigations at theoretical and empirical levels may confirm the value of Chinese philosophy to human well-being.

Lauren Pfister raises issues about the natural environment and problematizes the lack of enquiry into these questions by scholars who work in traditional Chinese philosophy. Through his meticulous research on existing literature, Pfister in "Environmental Ethics and Some Probing Questions for Traditional Chinese Philosophy" provides implicating evidence for this charge: there is noticeable gap in the literature by Chinese philosophers in the modern and contemporary periods about ethical approaches to technology and the impact of technological advancement on humankind and ecological well-being more generally. This is of particular concern given that traditional Chinese philosophy emphasizes benevolent humanity (Confucianism), is preoccupied with life and nature (Daoism), and articulates anthropocosmic perspectives (Confucianism and neo-Confucianism). Pfister's discussion suggests a lack of foresight or creativity, perhaps, on the part of Chinese philosophers to respond to changing paradigms and needs in the modern world. Indeed, were we to attend to these questions, we might quite possibly discover that Chinese philosophy offers important perspectives on technology that differ significantly from those in Western philosophy, ethics, and science. Literature on Chinese philosophy intimates that there is a wealth of insights to be harnessed in relation to insights on technology and the 
environment; even a fleeting consideration of the conceptual framework of the Yijing alerts us to the integrated nature of the natural world and human life. Pfister's challenge should be taken up especially as the condition of the natural environment is one of the most urgent issues in the world today.

Finally, in "Virtues of Junzi," Antonio S. Cua ${ }^{2}$ presents a picture of a paradigmatic Confucian individual, the junzi. In his description of the junzi, he articulates a comprehensive view of the Confucian moral program and how different Confucian virtues come together in this paradigmatic person. Cua revitalizes Confucian ethics by considering how the paradigmatic person might deal with problems in ethical life. His discussion brings out the active aspect of Confucian life, in terms of the junzi's cultivation, embodiment, and realization of virtues. He is mindful of the centrality of historical and cultural tradition in conceptions of ethics and therefore emphasizes the need to engage with ethical issues at both theoretical and practical levels. Cua's analysis is cautious as he admits that his account of Confucian ethics proposes an idealized rather than empirical unity of virtues. In light of actual experiences, some of these virtues, for instance, virtues of character and virtues of intelligence, might come into conflict. He suggests that in order to resolve some of these issues, we need a broader understanding of ethics in light of notions of human well-being and spirituality, society, government, and human good. In this regard, his picture of the junzi as a skilled deliberator with principled moral commitments is not simply a dated Confucian ideal; the junzi could well be a person in the contemporary world who is morally cultivated and capable of dealing with evolving and new situations.

All of the articles in this anthology share the feature of open inquiry in that their discussions generate more questions than answers. The articles impress on the need for further inquiries in Chinese philosophy especially in engaging with emergent issues of the present, in conference with other disciplines, and in dialogue with other philosophical traditions.

In closing, I would like to thank Professor Chung-ying Cheng, Editor-in-Chief of the Journal of Chinese Philosophy, for this special opportunity to coordinate and edit this volume. I would also like to express my gratitude to the contributors to this volume, all of whom have been wonderfully cooperative and generous with their time. Dr. Linyu Gu, Managing Editor of the Journal of Chinese Philosophy, has provided warm and invaluable support and guidance from the very inception of this volume. 


\section{ENDNOTES}

1. A number of articles in this collection (by Sivin, Lai, Pfister, Cheng) were presented at the International Society for Chinese Philosophy Conference held at the University of New South Wales in Sydney, Australia, in July 2005. The theme of the conference, "Chinese Philosophy and Human Development in the 21st Century," drew attention to the wealth of insights afforded by Chinese philosophy.

2. Professor Antonio S. Cua passed away on March 27, 2007. His article included in this volume, which he sent to me on March 6,2007, may have been his last completed work. Professor Cua was a deeply loved, admired, and respected teacher and scholar in Chinese philosophy and his outstanding contributions to the field will continue to influence future research for many years to come. 